\title{
The Effect of 5 Organophosphate Pesticides on the Growth of Chlorella vulgaris Beyerinck [Beijerinck] 1890
}

\author{
Burak ÖTERLER \\ Trakya University, Faculty of Science \\ Department of Biology, 22030, Edirne/TURKEY \\ burakoterler@trakya.edu.tr \\ Meriç ALBAY \\ İstanbul University \\ Faculty of Fisheries, İstanbul/TURKEY
}

\begin{abstract}
This work examines the effects of five pesticides on Chlorella vulgaris. For this purpose, C. vulgaris cultures were exposed to 5 pesticides (azinphos-methyl, malathion, parathion, terbufos, trichlorfon) of different concentrations for 96 hour. After exposure, EC 50 values, culture growth, chlorophyll_a, dry weight and pesticide accumulation analysis were performed. The results indicated that average toxicity of the five pesticides were as malathion > parathion > terbufos > azinphos-methyl > trichlorfon order. However, the statistical analysis revealed that the degree of effects of the effective pesticides on Chlorella vulgaris was determined to be ranked as azinphos-methyl > trichlorfon > terbufos > parathion-ethyl > malathion. The result obtain in GC/MS show that all pesticides were accumulated in C. vulgaris in high amounts. However, the current results need further data to conclude whether this accumulation is due to an absorbtion by an algae cell itself to an accumulation on cell surface. Terbufos was found to accumulate in high amounts in the C. vulgaris. There was a strong variance between toxicity and ecological risk.
\end{abstract}

Keywords: Chlorella vulgaris, pesticides, acute toxicity tests, GC/MS analysis

\section{INTRODUCTION}

Human being have been in a struggle to take the environment in hand; and nowadays they get incredible opportunities in terms of buying products, standard of living, settlement, increased their effect on environment geometrically and endanger their own existence. Especially in last 50-60 years, development of chemicals in industry and producing highly effective chemicals had an effect on ecosystems' balance. Human population is inevitably exposed to environmental pollution through airdegraded products, water, the soil and food and their introduction into the food chain [1]. When a pesticide is released into the environment many things happen to it. Sometimes, releasing pesticides into the environment can be harmful, as not all of the applied chemical reaches the target site [2].

Pesticides used for agricultural activities have quite negative effects other than the target organisms they affect when they turn back to the lakes or rivers by irrigation water or precipitation. When the studies on aquatic organisms analyzed, these studies are seen to be mostly concentrated on the organisms which represents the top level of food chain. By returning to the surface waters of the pesticides used for agricultural activities, one of the first organisms affected is the phytoplanktonic organisms constituting the first level in the food chain [3].

The Planktonic algae, which are the primary producers, have an important role in the aquatic environment. As they are the main component of the aquatic food chain and they constitute a group of organism that have a key role, they are very important on correct structuring and working of ecosystem. Moreover, planktonic algae are very important indicators used for different effects of the matter (chemicals) released to the aquatic environment [4].

If we compare many chemicals in terms of sensitivity, it is known that the sensitivity of algae and cyanobacteria are high [5]. In terms of ecological manner, most of the aquatic food webs and the nutrients and phosphorus cycling have key roles with their ecological status $[6,7]$. 
The toxicological states of pesticides on green algae have been reported. For the evaluation of the effects of environmental pollutants on algal communities, there is restricted applicability for the tests on specific algae species. These algal communities consist of a wide range of species having different sensitivity levels [8]. There are a few studies conducted about the comparative sensitivity of pesticides about several green algae $[9,10]$. In the current work, to examine the effects of five organophosphates pesticides on Chlorella vulgaris Beyerinck [Beijerinck] 1890, they are tested in terms of the comparison on differential sensitivity of pesticides.

\section{Material ANd Method}

\subsection{Chemicals}

All of the Analytical standards of pesticides were supplied by Dr. Ehrenstorfer (Germany) and their chemical classes and different primary modes of action [11] are listed in table 1 . The pesticides tested were dissolved with a little acetone, methanol, or distilled water.

Table1. Selected pesticides and their properties.

\begin{tabular}{|l|l|l|l|}
\hline Insecticides & CAS No & Formulation & Dr.Ehrenstorfer cat. no \\
\hline AZIPM (Azinphos-methyl) & $86-50-0$ & C10H12N3O3PS2 & C 10365000 \\
\hline MALATHION & $121-75-5$ & C10H19O6PS2 & C 14710000 \\
\hline PARATHION-Ethyl & $56-38-2$ & C10H14NO5PS & C 15880000 \\
\hline TERBUFOS & $13071-79-9$ & C9H21O2PS3 & C 17270000 \\
\hline TRICHLORFON & $52-68-6$ & C4H8C13O4P & C 17680000 \\
\hline
\end{tabular}

\subsection{Algal Strains and Culture Conditions}

The green alga Chlorella vulgaris Beyerinck [Beijerinck] 1890, was selected for the toxicity tests. $C$. vulgaris was kindly supplied by Culture Collection of Algae and Protozoa (CCAP) (Scotland, UK) [12]. Culture number of $C$. vulgaris, CCAP 211/11B and was grown in a medium recommended by the 3N-BBM+V (Bold Basal Medium with 3-fold Nitrogen and Vitamins; modified). Receipt was given CCAP internet cite (http://www.ccap.ac.uk/media/documents/3N_BBM_V.pdf). The culture medium was sterilized at $121^{\circ} \mathrm{C}$, for $30 \mathrm{~min}[10,13]$. Single cells of algae were propagated photoautotrophically in a $2500 \mathrm{ml}$ Erlenmeyer flask containing $1500 \mathrm{ml}$ liquid, kept on a shaked by hand twice a day. Cultures were maintained in the same liquid medium at a temperature of $23 \pm 2{ }^{\circ} \mathrm{C}$ and a illuminated with cool-white fluorescent lights of $8000 \mathrm{~lx} \mathrm{~cm}^{-2}$ and Photosynthesis photon flux (PPF) $53 \mu \mathrm{mol} \mathrm{m} \mathrm{s}^{-1}$ on a $12 \mathrm{~h}$ light-dark cycle $[7,10,14,15,16,17,18,19,20,21]$. Light intensity was measured by International Light RPS 900 model spektroradyometer in to the climate cabin. Acording to Photosynthesis photon flux (PPF) calculated to Ge et al. [22].

\subsection{Test Methods and Cell Experiments}

The experiments are planned to have 3 repetitions. The experiments are completed in 3 different pesticide concentrations as 12. hour, 24. hour, 48. hour, 72. hour and 96. hour, in accordance with ASTM, ISO 8692 and OECD 201 standards [23, 24, 25, 26]. At the beginning of the experiment, in other words 0.hour, in sterile conditions $20 \mathrm{ml}$ 's of culture samples taken from each testing set accordingly the conditions indicated above. The most suitable wavelength to use for monitoring culture growth was $680_{\mathrm{nm}}$; Kasai (1993) reported that cell numbers and OD680 $0_{\mathrm{nm}}$ were highly correlated [27]. To identify the spectral growth rates, in spectrophotometer, brand is Cecil and the model is CE9200, the absorbance values are measured $\left(\mathrm{OD}_{680 \mathrm{~nm}}=0,050\right)$, cell counting is performed by repeating three times Thoma cell counting chamber, from this sub sample a specific volume is taken and chlorophyll_ $a$ amount is measured and remaining sample is filtered through the whatmann $\mathrm{GF} / \mathrm{C}$ filter paper with $4,7 \mathrm{~mm}$ diameter and dry weight is determined. The filtrate filtered through the filter paper is gathered in the propilen tubes of $50 \mathrm{ml}$, and stored in deep-freezer at $-85{ }^{\circ} \mathrm{C}$ until their pesticide analyses are done. At the 12. hour, 24. hour, 48. hour, 72. hour and 96.hour of the experiment, same processes are repeated.

In taking the samples and analyses of the measures, EPA 8141 method was used and the measurements are performed using Back Detector (NPD) of 6890N Model GC/MS, with the brand Agilent Technologies, which is in Marmara TÜBİTAK Research Center [28]. The device has the helium gas as carrier gas and its oven temperature adjusted to $275{ }^{\circ} \mathrm{C}$. In the device 820821 Model, with 30 meter height and Retsek brand, column was used. The statistical analyses of the data obtained from the experiments, M.S. Excel 2003, Dunnet (during the calculation of $\mathrm{EC}_{50}$ values) and S.P.S.S programs, one way ANOVA analyses, Student Newman Keul's Test and T Test are used. 


\section{RESUltS}

The $96 \mathrm{~h} \mathrm{EC}_{50}$ values were calculated using linear regression analysis of transformed pesticide concentration as natural logarithm data versus percent inhibition ratio. Acute toxicity of 5 pesticides and growth rates to the green algae $C$. vulgaris is summarized in Table 2 . According to $\mathrm{EC}_{50}$ values of C. vulgaris, malathion> parathion-ethyl > terbufos > azipm.> trichlorfon. The average accumulation of those pesticides on the C. vulgaris were given table 3 .

Table2. Compare the pesticide toxicity (EC50 value) and growth rate.

\begin{tabular}{|l|l|l|}
\hline Insecticides & $\mathbf{E C}_{\mathbf{5 0}}$ & Growth Rate $\mathbf{K}_{\mathbf{1}}$ \\
\hline Control & 0 & 6.15 \\
\hline AZIPM (Azinphos-methyl) & $100.71 \pm 17$ & 1.28 \\
\hline MALATHION & $314.68 \pm 13$ & 3.28 \\
\hline PARATHION-Ethyl & $273.47 \pm 16$ & 2.43 \\
\hline TERBUFOS & $256.66 \pm 22$ & 3.6 \\
\hline TRICHLORFON & $97.08 \pm 12$ & 2.59 \\
\hline
\end{tabular}

Table3. Pesticides accumulation amount on C. vulgaris, end of the 96 hour.

\begin{tabular}{|l|l|l|}
\hline Insecticides & Low Con. & High Con. \\
\hline AZIPM (Azinphos-methyl) & & 100 \\
\hline MALATHION & 80.44 & \\
\hline PARATHION-Ethyl & 79.62 & \\
\hline TERBUFOS & 82.25 & \\
\hline TRICHLORFON & & 90.34 \\
\hline
\end{tabular}

Either too low or too high; $\mathrm{pH}$ is causing cellular functions to deterioration; thus the algal development will be very slow. The $\mathrm{pH}$ interval is between 7 and 9 for the algae species which are generally cultured, the optimum $\mathrm{pH}$ interval is between 8.2-8.7. In our study the optimum $\mathrm{pH}$ interval is provided for the mediums (Figure 1).

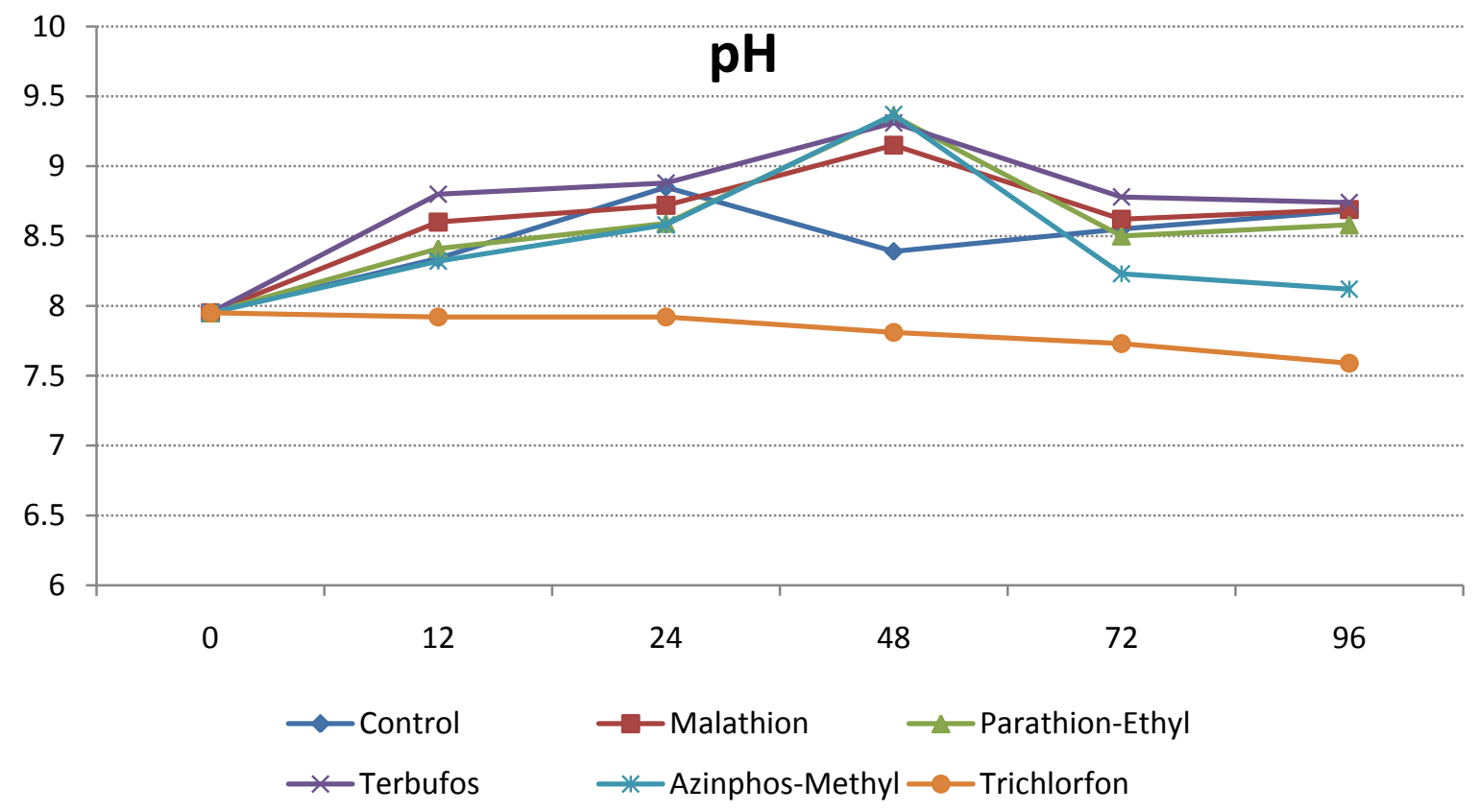

Figure1. For Chlorella vulgaris, average hourly $\mathrm{pH}$ measurements values.

Being on average $2042.4 \mu \mathrm{g} \mathrm{L}^{-1}$ at the beginning of the inhabitation experiments, Chlorophyll_a quantity is measured as $4750.8 \mu \mathrm{g} \mathrm{L}^{-1}$ on average at the end of the experiment. In the other experiment groups which is treated with pesticides, at the end of 96 hours Chlorophyll_a quantity is found to be highest in Malathion $\left(1820.4 \mu \mathrm{g} \mathrm{L}^{-1}\right)$ and lowest in Azinphos-methyl $\left(1021.2 \mu \mathrm{g} \mathrm{L}^{-1}\right)$. Results were given figure 2 . 


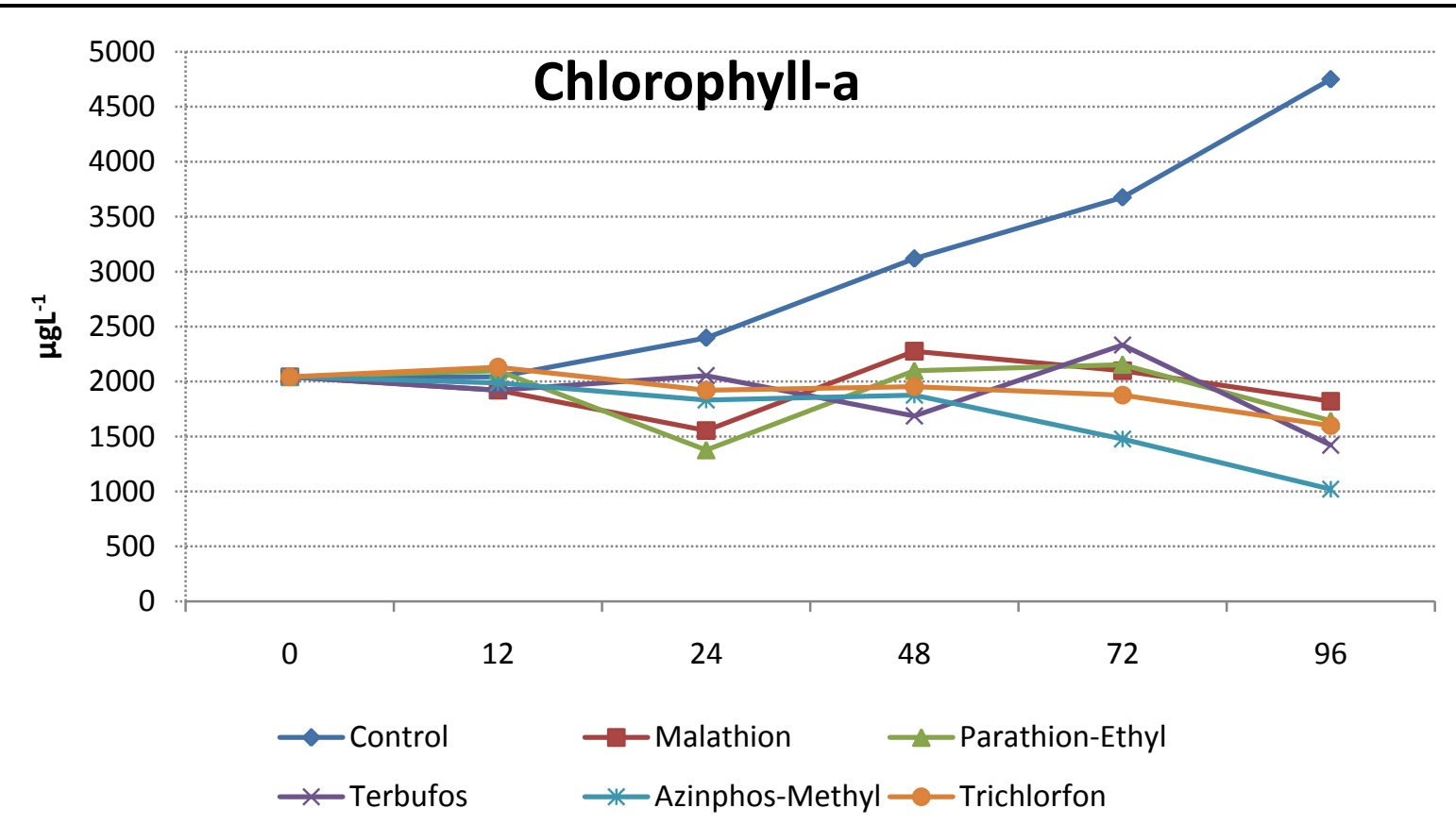

Figure2. Average alteration amount of Chlorophyll_a amounts of C vulgaris in the experiment sets in 96 hours.

For the wave lengths used for the measurement of development spectrophotometrically, in the wave length $\mathrm{OD}=680_{\mathrm{nm}}$, absorbance is at the beginning measured as $\mathrm{OD}=0.346$ and at the end of 96 . hour it is measured as $\mathrm{OD}=0.751$. At the end of the experiments the highest absorbance is found to be in parathion-ethyl $(\mathrm{OD}=0.486)$, the lowest is in Azinphos-methyl $(\mathrm{OD}=0.279 \mathrm{~nm}$ ) (Figure 3). For the cell number, during the standard fast growing stage of control group, the highest cell number in $\mathrm{mm}^{3}$ is found in Malathion (3223 ind $\mathrm{mm}^{3}$ ), the lowest is in Azinphos-methyl (2266 cell $\mathrm{mm}^{3}$ ) (figure 4).

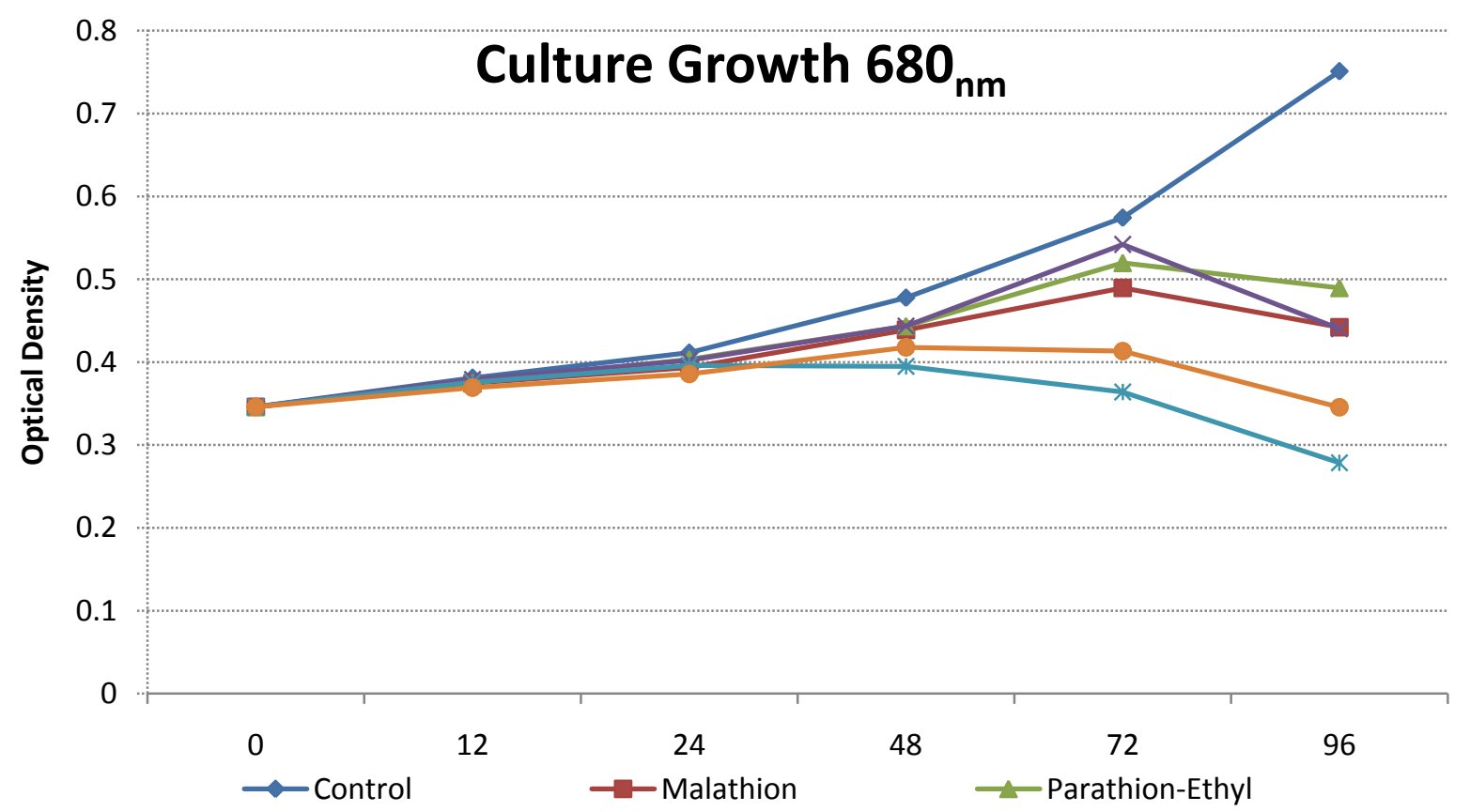

Figure3. For Chlorella vulgaris, Average Hourly Alteration Amounts of Spectrophotometric Absorbance Values for $680_{n m}$. 
The Effect of 5 Organophosphate Pesticides on the Growth of Chlorella vulgaris Beyerinck [Beijerinck] 1890

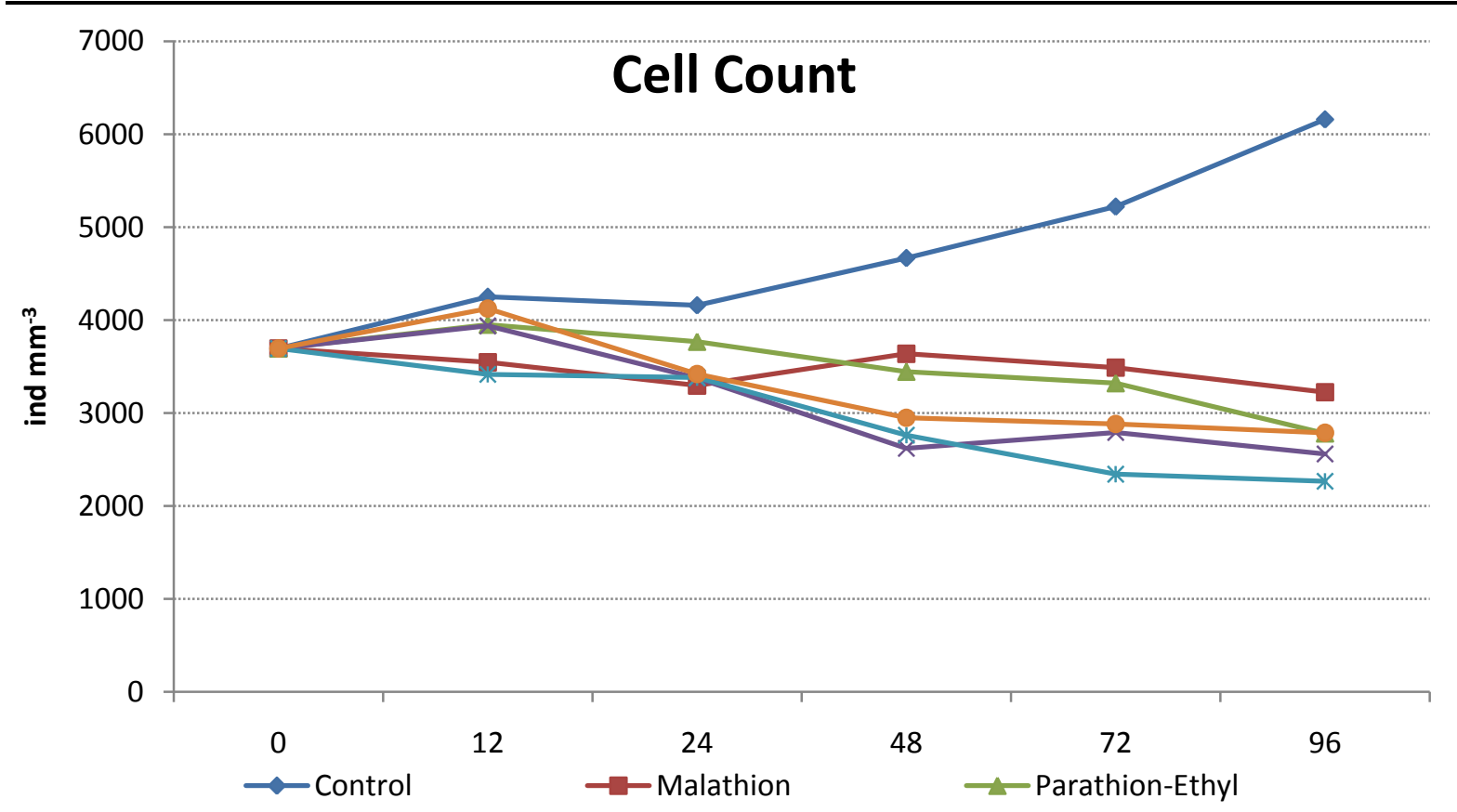

Figure4. Alive cell number per $\mathrm{mm}^{3}$ of Chlorella vulgaris for 96 Hours of Average Alteration Amounts.

Being on average $0.1 \mathrm{~g} \mathrm{~L}^{-1}$ at the beginning of the inhabitation experiments, dry weight quantity is measured as $0.38 \mathrm{~g} \mathrm{~L}^{-1}$ on average at the end of the experiment. In the other experiment groups which is treated with pesticides, at the end of 96 hours dry weight quantity is found to be highest in Trichlofon $\left(0.29 \mathrm{~g} \mathrm{~L}^{-1}\right)$ and lowest in Malathion $\left(0.22 \mathrm{~g} \mathrm{~L}^{-1}\right)$. Results were given figure 5.

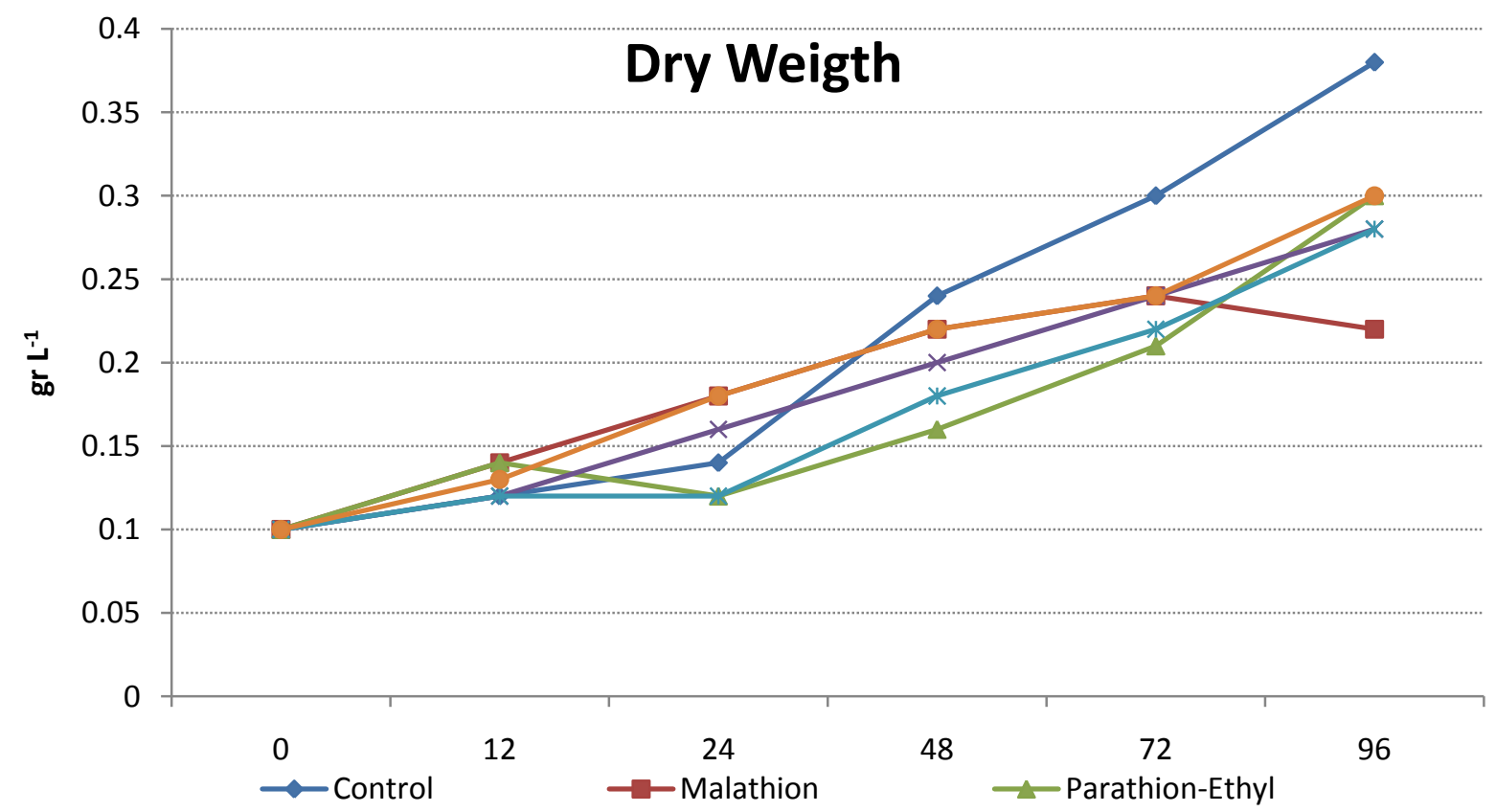

Figure5. Average alteration amount of dry weight amounts of $C$ vulgaris in the experiment sets in 96 hours.

When it is analyzed statistically, it is seen that the alteration in Chlorophyll_a quantities of Chlorella vulgaris is as Terbufos > Trichlorfon > Azinphos-methyl > Parathion ethyl > Malathion. For the quantities of Chlorophyll_a, these results are commented as meaningful statistically according to $\mathrm{P}<0,001$.

\section{Discussion}

At the end of the experiments, in the practices of low quantity of pesticide applications, this pesticide addition in Chlorella vulgaris induced all pesticides for Chlorophyll_a formation for the first 24 hour, 
and enhanced photosynthesis. But in time there is no specific increase in spectrophotometric absorbance and in cell number. But in 48., 72. and 96.hours the development slowed down. In low concentration $C$. vulgaris is affected mostly from Azinphos-Methyl and Trichlorfon. For the concentration practiced in low concentration experiments for $C$. vulgaris, there was hormonal effect in the first 24 hours.

In the practices with high amount of pesticide applications, parathion-ethyl and azinphos-methyl made a very few progress for only 12 hours in the culture compared to the control groups, but at the end of 96.hour all the pesticides started their progress of their own cultures. In the practices with low amount of pesticide applications, the most effective pesticide on $C$. vulgaris is seen to be azinphos-methyl. This is followed by terbufos, trichlorfon, parathion-ethyl and malathion, relatively.

The pesticides added to the culture are absorbed by algae and obtain the qualification of nutrient used for algae growing and increasing of the protein content. But if these pesticides are applied in high concentrations, excluding the algae's arrangement borders, as a result of the increase in concentration algae culture growing is slowed down gradually. As a result, depending on degeneracy of the algae cell structure, the chloroplast structure in algae cells started to deteriorate and the typical horseshoe shaped chloroplast of Chlorella vulgaris shrinked and is pulled to an edge of the cell wall. By the time the color of the cultures treated with pesticides started to be lightened relative to the control group. Chlorophyll_a content is dropped and the synthesis in the cells decreased, which caused the lowering of protein and other organic matter content. The results obtained at this study are similar with the results of the study of Nie et al., (2002), Ou et al., (2003) and Xia et al., (2007) [20, 29, 30]. Therefore, the toxicity of the pesticide on algae cells and the degeneration of the pesticide by algae cells are coming into question during the interaction of algae and pesticides.

When the concentrations of algae cells and pesticides are in different levels, the functions they have are in different dominance. Because of this, different effects and functions are displayed. When the pesticide concentration is less in Chlorella vulgaris, pesticide degenerates and is absorbed by algae cells as if it is nutrient; but then the toxic effect of the pesticide emerges and limits the growth of algae.

According to the pesticides used in the study of which is tested according to one way ANOVA analysis and Student-Newman-Keul's method, if we look at the most resistant organism, pesticides used at the end of the statistical calculations the features of the inhibit, the most effective pesticide for Chlorella vulgaris is determined to be Azinphos-Methyl > Trichlorfon > Terbufos $>$ Parathion-Ethyl $>$ Malathion $(\mathrm{p}=<0,01)$.

It is known that organophosphate insecticides of the plant cytochrome in terrestrial plants are inhibiting the P450 monooxygenases. Varsano et al., (1992) determined that if the P450 monooxynegenase in inhibited the sensibility of trizine herbicide in corn increases [31]. There are evidences that in high plants P450 monooxynegenase can result in the detoxification of xenobiotics [32]). Similarly, Thies et al., (1996) argued that there is a great variety of P450 enzymes and degradation of metflurazone depends on P450 [33]. According to this, it is highly possible that the degradation of xenobiotics in algae progresses as it does in high plants [34].

After the calculation of the values measured in GC-NPD device, generally chosen 5 pesticides are collected in high amounts by $C$. vulgaris. It is not concluded yet that this accumulation is either absorbed by an algae cell or kept on the surface area. While terbufos is accumulated in high levels at the test organism, azinphos-methyl is determined to be almost disappeared in C. vulgaris. After 96 hours when the concentrations which caused $50 \%$ of test organisms to die is checked, it is possible to say that Trichlorfon is more effective when compared to the other pesticides used for the studies on green algae.

The algae, one of the most important factors affecting soil fertility and the essential nutrient for the fishes in aquatic environment, are expanded to a broad area in the nature [35]. Algae have a key role in aquatic environments. As the pesticides are used widely worldwide, survival, development and reproduction of algae are largely affected. Therefore, the studies on the effects of the pesticides to algae are very important; on the other hand when the pesticides are used in the areas where algae live, algae show up as an indicator for the evaluation of the environmental safety. Recently, after the inhabitation effects of the insecticides on algae cultures came to light, the studies on this issue are expanded. When previous studies are investigated, it is determined that the results of these studies shows similarity with our study results. 
Algal water bloom can be defined as the change of the community structure of some algae species in aquatic environments and excessive increase of their numbers. Resulting in excessive increase of algae, these species response to the environmental pollutants is very important for ecosystem dynamics. With the effect of pollutants there might be a shift in community structure and this shift would create a risk for the balance of the ecosystem. Mesocosm experiments conducted on more than one species can be seen as more suitable but it is hard to comment on the results properly. But the toxicity tests conducted on single species may not be enough for the evaluation of biological data resources. However, in the cases where ecosystem modelling is not performed, it is convenient to interpret the effects of these pollutants ecologically.

\section{ACKNOWLEDGEMENT}

This research has been supported by TÜBAP-752 project. The GC/MS measurements and calculations were performed by TÜBİTAK Marmara Research Center, Environment and Cleaner Production Institute.

\section{REFERENCES}

[1] Gomez M.J., Herrera S., Sole D., Garcia-Calvo E. and Fernandez Alba A. R. Automatic searching and evaluation of priority and emerging contaminants in wastewater and river water by stir bar sorptive extraction followed by comprehensive two-dimensional gas chromatographytime-of-flight mass spectrometry, Anal. Chem., 83, 2638-2647, (2011).

[2] Cessna A. J. Pesticides in the environment: Real or Imagined, Agriculture and Agri-food Canada, Research Centre, Lethbridge, AB, (2009).

[3] Crosby D. G. Environmental chemistry: An overview, Environ. Toxicol. Chem., 1,1-11, (1982).

[4] Burkiewicz K., Synak R. and Tukaj Z. Toxicity of Three Insecticides in a Standard Algal Growth Inhibition Test with Scenedesmus subspicatus, Bull. Environ. Contam. Toxicol., 74, 1192-1198, (2005).

[5] Aguilera-Del Real A., Valverdegarcia A., Fernandez-Alba A. R. and Camacho-Ferre F. Behaviour of endosulfan residues in peppers, cucumbers and cherry tomatoes grown in greenhouse: evaluation of decline curves, Pesticide Science, 51,194-200, (1997).

[6] Kallqvist T. and Svenson A. Assessment of ammonia toxicity in tests with the microalga, Nephroselmis pyriformis, Chlorophyta, Water Research, 37, 477-484 (2003).

[7] Sabater C. and Carrasco J. Effects of pyridaphenthion on growth of five freshwater species of phytoplankton, Chemosphere, 44, 1775-1781 (2001).

[8] Sanchez P and Tarazona J. V. Development of a multispecies system for testing reproductive effects on aquatic invertebrates. Experience with Daphnia magna, Chironomus prasinus and Lymnaea peregra, Aquatic Toxicol., 60, 249-256 (2002).

[9] Ma J., Lu N., Xu R., Wang Y. and Qin W. Differential response of eight cyanobacterial and green algal species, to carbamate insecticides, Ecotoxicol. Environ. Saf., 63, 268-274, (2006).

[10] Ma J., Wang P., Chen J. and Sun Y. Differential response of green algal species Pseudokirchneriella subcapitata, Scenedesmus quadricauda, Scenedesmus obliquus, Chlorella vulgaris, Chlorella pyrenoidosa to six pesticides, Pol. J. Environ. Stud., 16, 847-851, (2007).

[11] Stoytcheva M. Pesticides-formulations, effects, fate, InTech, Chapters published. (2011) pp. 822.

[12] CCAP (The Culture Collection of Algae and Protozoa) (2016). http://www.ccap.ac.uk/media/ documents/3N_BBM_V.pdf (27 March 2016).

[13] Ma J., Tong S., Wang P. and Chen, J. Toxicity of Seven Herbicides to the Three Cyanobacteria Anabaena flos-aquae, Microcystis flos-aquae and Mirocystis aeruginosa, International Journal of Environmental Research, 4(2), 347-352, (2010).

[14] Junghans M., Backhaus M., Faust M., Scholze M. and Grimmea L. H. Application and validation of approaches for the predictive hazard assessment of realistic pesticide mixtures, Aquatic Toxicology, 76, 93-110, (2006).

[15] Lockert C. K., Hoagland K. D. and Siegfried B. D. Comparative Sensitivity of Freshwater Algae to Atrazine, Bull. Environ. Contam. Toxicol., 76, $73-79$ (2006). 
[16] Konstantinou I. K., Hela D. G. and Albanis T. A. The status of pesticide pollution in surface waters (rivers and lakes) of Greece. Part I. Review on occurrence and levels, Environmental Pollution, 141, 555-570, (2006).

[17] Rose M. T., Sanchez-Bayo F., Crossan A. N. and Kennedy I. R. Pesticide removal from cotton farm tailwater by a pilot-scale ponded wetland, Chemosphere, 63, 1849-1858, (2006).

[18] Scragg A. H. The effect of phenol on the growth of Chlorella vulgaris and Chlorella VT-1, Enzyme and Microbial Technology, 39, 796-799, (2006).

[19] Schreiber U., Quayle P., Schmidt S., Escher B. I. and Mueller J. F. Methodology and evaluation of a highly sensitive algae toxicity test based on multiwell chlorophyll fluorescence imaging, Biosensors and Bioelectronics, 22, 2554-2563, (2007).

[20] Xia-Li W., Xiao-Qing Y., Yong-Hong L. and Yuan-Yan D. Effect of bensulfuron-methyl on growth of chlorella pyrenoidosa. Agricultural Sciences in China, 6(3), 316-321, (2007).

[21] Hong Y., Hu H. Y. and Li F. M. Growth and physiological responses of freshwater green alga Selenastrum capricornutum to allelochemical ethyl 2-methyl acetoacetate (EMA) under different initial algal densities, Pesticide Biochemistry and Physiology, 90, 203-212(2008).

[22] Ge S., Smith R. G., Jacovides C.P., Kramer M. G. and Carruther R. I. Dynamics of photosynthetic photon flux density (PPFD) and estimates in coastal northern California. Theor Appl Climatol (2011), 105,107-118.

[23] ASTM. Standard guide for conducting static 96-h toxicity tests with microalgae, E 1218-90, (1993).

[24] International Organisation for Standardisation. ISO 8692 Water quality-Algal growth inhibition test, (2012).

[25] International Organisation for Standardisation. ISO/DIS 14442. Water quality-Guidelines for algal growth inhibition tests with poorly soluble materials, volatile compounds, metals and waster water, (2014).

[26] OECD. Test No. 201: Freshwater Alga and Cyanobacteria, Growth Inhibition Test, OECD Guidelines for the Testing of Chemicals, Section 2, OECD Publishing, (2011), Paris.

[27] Kasai F., Takamura N. and Hatakeyama S. Effect of simetryn on growth of various freshwater algal texa, Environ. Pollut., 79, 77-83, (1993).

[28] EPA, United States Environmental Protection Agency. 2011. Pesticides industry sales and usage.2006 and 2007 market estimates. Washington DC 20460.

[29] Nie X. P., Lan C. Y., Lin L., Huang M. H. The effects of aroclor 1254 on the growth of Chlorella pyrenoidosa and Scenedesmus obliquus, ACTA Scientiarum Naturalium Universitatis Sunyatseni, 41,68-71, (2002).

[30] Ou X. M., Lei M. X., Huang M. Z., Wang Y. L., Wang X. G. and Fan D. F. Effects of novel sulfonylurea herbicide HNPC-(29908) on growth of green algae Chlorella pyrenoidosa, Chinese Journal of Pesticide Science, 5, 16-23, (2003).

[31] Varsano R., Rabinowitch H. D. and Ruben B. Mode of action of piperonyl butoxide as herbicide synergist of atrazine and terbutryn in maize. Pest. Biochem. Physiol. 44, 174-182, (1992).

[32] Baerg R. J., Barrett M. and Polge N. D. Insecticide and insecticide metabolite interactions with cytochrome P450 mediated activities in maize, Pestic Biochem. Physiol., 55,10-20, (1996).

[33] Thies F., Backhaus T., Bossmann B., Grimme L. H. Xenobiotic biotransformation in unicellular green algae - Involvement of cytochrome P450 in the activation and selectivity of the pyridazinone pro-herbicide metflurazon. Plant. Physiol., 112, 361-370, (1996.).

[34] Munkegaard M., Abbaspoor M. and Cedergreen N. Organophosphorous insecticides as herbicide synergists on the green algae Pseudokirchneriella subcapitata and the aquatic plant Lemna minor, Ecotoxicology, 17, 29-35, (2008).

[35] Yan G., Shen G., Yan X. and Peng J., Study on ecotoxicology for pesticides to algae 11: toxic effect. Advances in Environmental Science, 7, 96- 106, (1999). 